\title{
Bridging and downstaging role of trans-arterial radio-embolization for expected small remnant volume before liver resection for hepatocellular carcinoma
}

\author{
Ahmed Shehta ${ }^{1,2}$, Jeong-Moo Lee ${ }^{1}$, Kyung-Suk Suh ${ }^{1}$, Hyo-Cheol Kim³ \\ Suk Kyun Hong ${ }^{1}$, Jae-Hyung $\mathrm{Cho}^{1}$, Nam-Joon $\mathrm{Yi}^{1}$, and Kwang-Woong Lee ${ }^{1}$ \\ ${ }^{1}$ Department of Surgery, Seoul National University College of Medicine, Seoul, Korea, \\ ${ }^{2}$ Liver Transplantation Unit, Gastrointestinal Surgery Center, College of Medicine, Mansoura University, \\ Mansoura, Egypt, ${ }^{3}$ Department of Radiology, Seoul National University Hospital, Seoul, Korea
}

\begin{abstract}
Backgrounds/Aims: To evaluate our initial experience of bridging role of trans-arterial radio-embolization (TARE) before major hepatectomy for hepatocellular carcinoma (HCC) in risky patients with small expected remnant liver volume (ERLV). Methods: We reviewed the data of patients with HCC who underwent major hepatectomy after TARE during the period between March and December 2017. Patients included had uni-lobar large HCC ( $>5 \mathrm{~cm})$ requiring major hepatectomy with small ERLV. Results: Five patients were included in our study. All patients were Child Pugh class A. A single session of TARE was applied in all patients. None developed any adverse events related to irradiation. The mean tumor size at baseline was $8.4 \mathrm{~cm}$ and $6.1 \mathrm{~cm}$ after TARE $(p=0.077)$. The mean $\%$ of tumor shrinkage was $24.5 \%$. ERLV improved from $354.6 \mathrm{ml}$ at baseline to $500.8 \mathrm{ml}$ after TARE $(p=0.012)$. ERLV percentage improved from $27.2 \%$ at baseline to $38.1 \%$ after TARE $(p=0.004)$. The mean $\%$ of ERLV was $39.5 \%$. The mean interval time between TARE and resection was 99.6 days. Four patients $(80 \%)$ underwent right hemi-hepatectomy and one patient $(20 \%)$ underwent extended right hemi-hepatectomy. The mean operation time was 151 minutes, and mean blood loss was $56 \mathrm{ml}$. The mean hospital stay was 13.8 days, and one patient (20\%) developed postoperative morbidity. After a mean follow-up of 15 months, all patients were alive with no recurrence. Conclusions: Yttrium-90 TARE can play a bridging role before major hepatectomy for borderline resectable HCC in risky patients with small ERLV. (Ann Hepatobiliary Pancreat Surg 2020;24:421-430)
\end{abstract}

Key Words: Trans-arterial radio-embolization; Major liver resection; Small remnant liver volume

\section{INTRODUCTION}

Liver resection and transplantation are the main lines of curative treatment for patients with hepatocellular carcinoma (HCC). Liver transplantation is applied for selected patients with early stage $\mathrm{HCC}$ with favorable tumor biology. ${ }^{1,2}$ Therefore, liver resection plays an important role in the treatment of HCC patients. However, many HCC patients are not candidates for liver resection at the time of diagnosis due to poor liver functions, multifocal tumor, small remnant liver volume or proximity to major hepatic vasculatures. ${ }^{3}$

Preoperative portal vein embolization (PVE) had been suggested before major liver resection to induce compensatory hypertrophy of the remnant liver before liver resection. PVE achieved satisfactory outcomes in terms of expected remnant liver volume (ERLV). ${ }^{4}$ However, some patients may lose the chance for resection due to progression of untreated tumor during the interval between PVE and liver resection. ${ }^{5-7}$

To overcome this problem, the concept of sequential selective trans-arterial chemoembolization (TACE) with PVE before major liver resection was introduced. This combination helps to control tumor progression during the period between intervention and liver resection. Also, it strengthens the effect of PVE by embolizing the arterio-

Received: March 23, 2020; Revised: July 13, 2020; Accepted: July 13, 2020

Corresponding author: Kyung-Suk Suh

Department of Surgery, Seoul National University College of Medicine, 101 Daehak-ro, Jongno-gu, Seoul 03080, Korea

Tel: +82-2-2072-3789, Fax: +82-2-766-3975, E-mail: kssuh2000@gmail.com

*Ahmed Shehta and Jeong-Moo Lee contributed equally to this work as co-first authors.

Copyright (C) 2020 by The Korean Association of Hepato-Biliary-Pancreatic Surgery

This is an Open Access article distributed under the terms of the Creative Commons Attribution Non-Commercial License (http://creativecommons.org/ licenses/by-nc/4.0) which permits unrestricted non-commercial use, distribution, and reproduction in any medium, provided the original work is properly cited. Annals of Hepato-Biliary-Pancreatic Surgery • pISSN: 2508-5778 • elSSN: 2508-5859 
portal shunts that may exist. ${ }^{8}$ However, this approach is associated with increased liver damage due to double occlusion of blood supply and the development of severe post-embolization syndrome. ${ }^{9,10}$

Yttrium-90 trans-arterial radio-embolization (TARE) had been introduced as a novel modality in the management of intermediate and advanced stage HCC. ${ }^{11,12}$ It involves selective intra-arterial delivery of radioactive microspheres to provide selective internal radiation to the tumor. This results in progressive tumor necrosis and shrinkage. From the surgical view, TARE therapy may help to increase resectability of HCC in high risk patients with small ERLV. TARE therapy induces hypertrophy of ERLV while controlling the primary tumor during the interval between TARE and liver resection. At the same time, it gives a good biologic test to evaluate the biologic behavior of the tumor after TARE therapy.

There are few reports about surgical resection of HCC following TARE therapy in patients with small ERLV. ${ }^{13-15}$ This study was conducted to evaluate our initial experience of the bridging role of TARE before major liver resection for HCC in high risk patients with small ERLV. We aimed to evaluate two main aspects. Firstly, the downstaging effect of TARE before major liver resection for HCC (the oncologic aspect). Secondly, the estimated remnant liver volume hypertrophy after TARE in risky patients with small ERLV (the safety aspect).

\section{MATERIALS AND METHODS}

We retrospectively reviewed the data of patients with HCC who underwent major liver resection after TARE therapy at Seoul National University Hospital (SNUH), Seoul National University, Korea during the period between March 2017 and December 2017.

The inclusion criteria in this study included:

1- Uni-lobar disease.

2- Tumor size exceeding $5 \mathrm{~cm}$ in diameter.

3- Required hemi-hepatectomy or extended hemi-hepatectomy (due to central location or close relation to major vascular structures) for curative liver resection but is associated with small ERLV (less than $30 \%$ of standard liver volume).

4- Age above 18 years old.

5- Preserved liver functions (Child-Pugh class A).

6- Good performance status (Eastern Cooperative Oncology Group performance status less than 2).

7- Absence of distant metastatic disease.

\section{Management protocol}

Management algorithm for the study patients is shown in Fig. 1. The treatment protocol was approved by institutional review board at SNUH and an informed consent was obtained from all patients before treatment.

\section{Evaluation before TARE}

Eligible patients were discussed in a multi-disciplinary meeting to evaluate the suitability to undergo TARE ther-

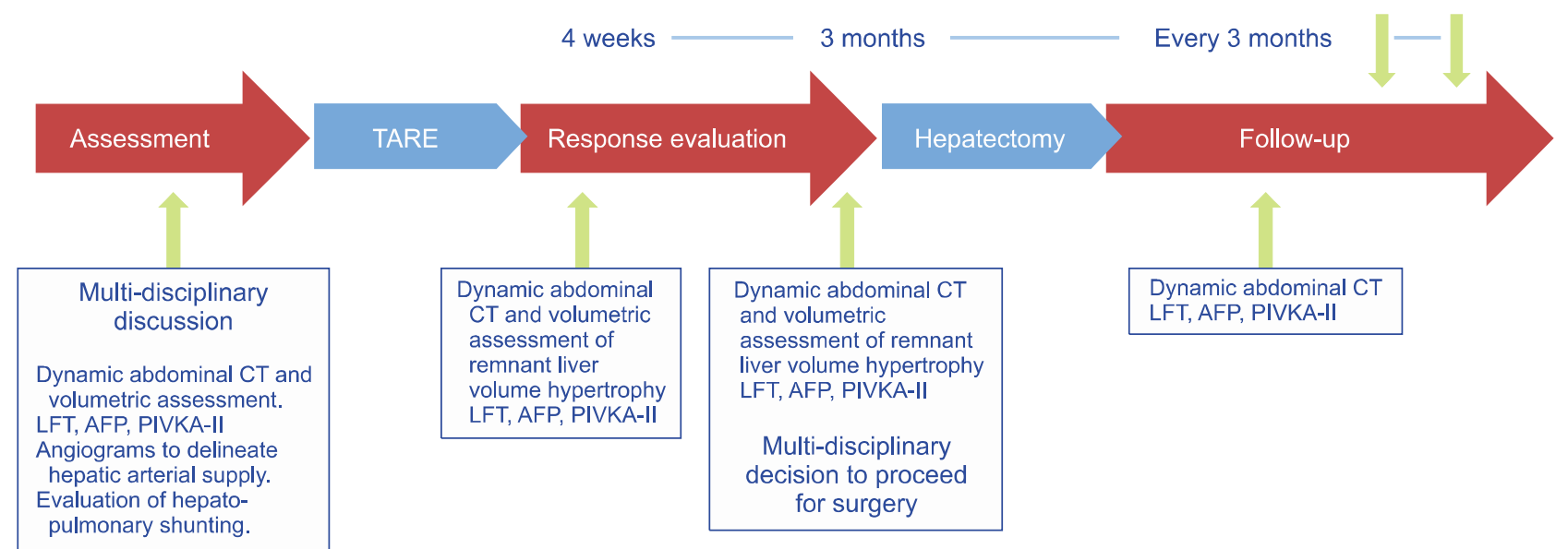

Fig. 1. Management algorithm of the study patients. TARE, trans-arterial radio-embolization; CT, computed tomography; LFT, liver function tests; AFP, alpha fetoprotein; PIVKA-II, protein induced by vitamin $\mathrm{K}$ absence or antagonist-II. 
apy within 4 weeks before the procedure. Eligible patients underwent baseline triphasic dynamic computed tomography and volumetric assessment using 3D virtual liver surgery planning software (Dr Liver ${ }^{\mathrm{TM}}$, POSTECH, Gyeongbuk, Korea). ${ }^{16}$ Also, eligible patients underwent baseline detailed laboratory evaluation including tumor markers (alpha fetoprotein (AFP) and protein induced by vitamin $\mathrm{K}$ absence or antagonist-II (PIVKA-II)).

Diagnostic angiography was performed to evaluate hepatic vasculature and possible ectopic supply for the tumor, and to detect collateral shunting from the liver to other organs. At the same time, technetium-99m-labeled macroaggregated albumin scan (99mTc-MAA) was performed to evaluate the hepatopulmonary shunting and the probability of pulmonary complications caused by TARE therapy.

\section{TARE procedure}

Yttrium-90 glass microspheres (TheraSphere ${ }^{\circledR}$, BTG International, London, United Kingdom) were infused via lobar hepatic artery to induce progressive ipsilateral tumor necrosis and shrinkage with gradual hypertrophy of contralateral lobe. If the tumor has a dominant tumor-feeding artery, additional radioactive microspheres were infused into the tumor-feeding artery to enhance anti-tumor effect. All patients were admitted to the hospital and commonly discharged 1 day after the procedure. The Medical Internal Radiation Dose method was used to calculate the target perfused tissue dose. The desired dose of treated liver volume ranged from 180 to $240 \mathrm{~Gy}$, and the estimated lung dose was less than $30 \mathrm{~Gy}{ }^{17,18}$

\section{Post-TARE follow up}

Patients were followed up in the outpatient clinic at 4 weeks and 3 months after TARE therapy. At 4 weeks visit, patients underwent physical examination, detailed laboratory evaluation including tumor markers, and triphasic dynamic computed tomography to assess the response to TARE therapy. At 3 months visit, patients underwent physical examination, detailed laboratory evaluation including tumor markers, and triphasic dynamic computed tomography and volumetric assessment with the same imaging technique used at the baseline evaluation. If the ERLV is more than $30 \%$ of the standard liver volume in absence of local or distant disease progression, surgical resection could be done. Tumor response and disease progression were evaluated using the modified RECIST criteria. $^{19}$

\section{Liver volumetric evaluation}

Volumetric assessment was performed for patients before (baseline) and after TARE therapy (3 month) using $3 \mathrm{D}$ virtual liver surgery planning software (Dr Liver ${ }^{\mathrm{TM}}$ ).

Volumetric assessment was performed based on planned surgical resection (hemihepatectomy or extended hemi-hepatectomy) Fig. 2.

Volumetric measurements were calculated as follow:

$\%$ Tumor shrinkage $=$

Tumor size pre-TARE - Tumor size post-TARE/Tumor size pre-TARE $\%$.

\% Expected Remnant Liver Hypertrophy=

Remnant liver volume post-TARE-Remnant liver volume pre-TARE/Remnant liver volume pre-TARE \%.

\section{Operative procedure and pathological analysis}

Liver resections were performed after about 3 months following TARE therapy. All major liver resections (hemi-hepatectomy or extended hemi-hepatectomy) were performed by senior liver surgeons using standard liver resection technique Fig. 2. Perihepatic inflammatory adhesions were found but these were easily dissected without injuries to any surrounding organs. Demarcation between treated and nontreated hemiliver was evident. Pedicle dissection and control of inflow structures was easily done without marked inflammatory changes at the pedicle. Parenchymatous dissection was performed by cavitron ultrasonic suction aspirator $\left(\mathrm{CUSA}^{\circledR}\right.$; Valleylab, Inc., Boulder, CO, USA). After surgery, patients were transferred to intensive care unit then to the ward. Postoperative complications were recorded and graded according to Clavien-Dindo classification. ${ }^{20}$ Resected liver specimens were examined pathologically, paying attention to the extent of necrosis of HCC and the presence of viable neoplastic tissue.

\section{Post-hepatectomy follow up}

After discharge, patients were followed up regularly in the outpatient clinic at 1 , and 3 months then every 3 months after liver resection. Follow up visits included physical examination, detailed laboratory evaluation in- 

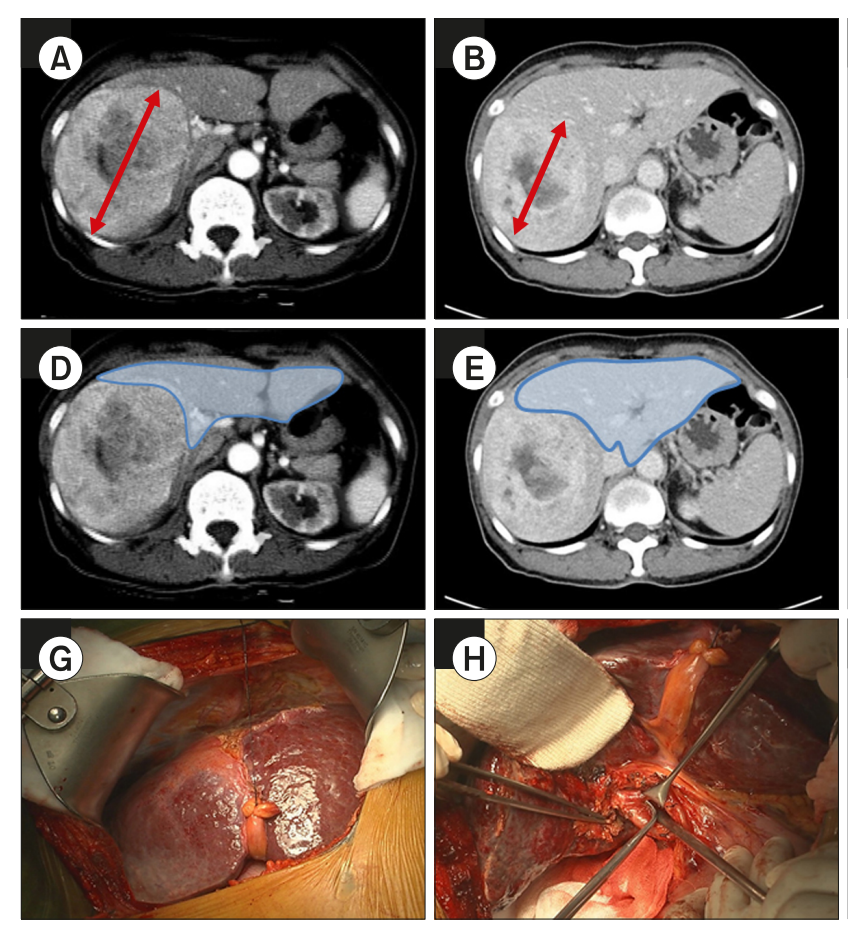
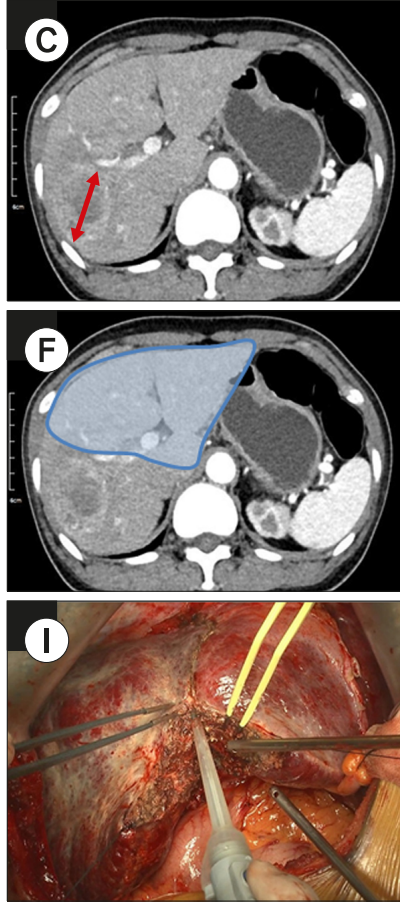

Fig. 2. (A-F) Computed tomography photos showing gradual tumor shrinkage (red line) and increased remnant liver volume (blue zone) after yettrium-90 transarterial radioembolization. (A and D) At baseline evaluation, (B and E) 4 weeks after trans-arterial radioembolization, and $(\mathrm{C}$ and $\mathrm{F})$ before liver resection. (G-I) Operative view of right hemi-hepatectomy after yettrium- 90 transarterial radioembolization. (G) Initial exposure with noted demarcation and inflammation on the right hemi-liver. $(\mathrm{H})$ Pedicle dissection and individual control of inflow structures. (I) Parenchymatous division by cavitron ultrasonic suction aspirator. cluding tumor markers, and triphasic dynamic computed tomography.

\section{Statistical analysis}

Continuous variables were expressed as mean \pm standard deviation. Tumor size and volumetric measurements were compared before and after TARE therapy by paired sample t-test. Survival was calculated to the time of the last follow up. Statistical analysis was performed using the SPSS 20 software (IBM, Chicago, IL, USA). A $p$-value less than 0.05 was considered statistically significant.

\section{RESULTS}

During the study period, 5 patients with HCC met the inclusion criteria and were included in our study. An informed consent was obtained from all patients before starting the treatment protocol.

\section{Baseline characteristics}

The basic characteristics of the study patients are shown in Table 1. The mean age was $55.2 \pm 10$ years. 4 patients $(80 \%)$ had underlying hepatitis $\mathrm{B}$ viral infection while 1 patient $(20 \%)$ had underlying hepatitis C viral infection. All patients were Child Pugh class A.

\section{Radiological and volumetric outcomes}

A single session of TARE therapy was applied in all patients. None of the study patients developed any adverse events related to irradiation. Radiological and volumetric data of the study patients at baseline and 3 months after TARE therapy are shown in Table 1 . The mean tumor size decreased from $8.4 \pm 2.8 \mathrm{~cm}$ at baseline to $6.1 \pm 1.4 \mathrm{~cm}$ 3 months after TARE therapy, and this was statistically non-significant $(p=0.077)$. The mean $\%$ of tumor shrinkage after TARE therapy was $24.5 \pm 15.7 \%$.

ERLV improved from $354.6 \pm 66.8 \mathrm{ml}$ at baseline to $500.8 \pm 138.6 \mathrm{ml}$ at 3 months after TARE therapy, and this was statistically significant $(p=0.012)$. Expected remnant liver percentage improved from $27.2 \pm 3.8 \%$ at baseline to $38.1 \pm 6.6 \%$ at 3 months after TARE therapy, and this was statistically significant $(p=0.004)$. The mean $\%$ of expected remnant liver hypertrophy after TARE therapy was $39.5 \pm 13.3 \%$.

\section{Operative and pathological outcomes}

The peri-operative and pathological outcomes of the study patients are shown in Table 2. The mean interval time between TARE therapy and surgical resection was $99.6 \pm 54.3$ days. The mean operation time was $151 \pm 52.7$ minutes, and mean blood loss was $56 \pm 26.1 \mathrm{ml}$. None of the patients received perioperative blood transfusion. The 
Table 1. Baseline characteristics, radiological and volumetric data of the study patients

\begin{tabular}{|c|c|c|c|c|c|c|}
\hline Variables & Case 1 & Case 2 & Case 3 & Case 4 & Case 5 & All cases \\
\hline Age (years) & 57 & 42 & 54 & 53 & 70 & $55.2 \pm 10.03$ \\
\hline Gender & Male & Male & Male & Male & Female & --- \\
\hline Body mass index $\left(\mathrm{kg} / \mathrm{m}^{2}\right)$ & 26.96 & 28.4 & 24.01 & 28.58 & 17.96 & $25.2 \pm 4.4$ \\
\hline Etiology & $\mathrm{HBV}$ & $\mathrm{HBV}$ & $\mathrm{HBV}$ & $\mathrm{HCV}$ & $\mathrm{HBV}$ & --- \\
\hline Child-pugh class & A & A & A & A & A & --- \\
\hline Platelets count $\left(* 10^{3} / \mu \mathrm{l}\right)$ & 186 & 170 & 145 & 119 & 230 & $170 \pm 42.08$ \\
\hline Serum bilirubin (mg/dl) & 0.4 & 0.6 & 0.3 & 0.8 & 0.7 & $0.56 \pm 0.21$ \\
\hline Serum INR & 1.06 & 1.05 & 1.02 & 1.02 & 0.92 & $1.01 \pm 0.06$ \\
\hline Serum ALT (IU/L) & 31 & 40 & 40 & 45 & 126 & $56.4 \pm 39.23$ \\
\hline Serum AST (IU/L) & 46 & 26 & 34 & 47 & 140 & $58.6 \pm 46.33$ \\
\hline Serum AFP (ng/ml) & 5 & 24 & 30.1 & 19.1 & 29360 & $5887.64 \pm 1312.45$ \\
\hline Serum PIVKA-II (mAU/ml) & 30731 & 4.8 & 936 & 2877 & 2129 & $7335.56 \pm 1314.67$ \\
\hline Indocyanine green retention $15 \mathrm{~min}$ & 19.9 & 14 & 8.2 & 27 & 2.5 & $14.32 \pm 9.61$ \\
\hline Fibroscan transient elastography (kpa) & 17.6 & 7.3 & 5.8 & 6.7 & 12.6 & $10 \pm 5.01$ \\
\hline \multicolumn{7}{|c|}{ Baseline radiological and volumetric evaluation } \\
\hline Liver status & Normal & Normal & Normal & Normal & Normal & --- \\
\hline Tumor location & S 5,6 & S 8 & S 7,8 & S 5 & S 6,7 & --- \\
\hline Proximity to major vascular structure & $\begin{array}{l}\text { Right portal } \\
\text { vein }\end{array}$ & $\begin{array}{l}\text { Middle } \\
\text { hepatic vein }\end{array}$ & No & $\begin{array}{l}\text { Right portal } \\
\text { vein }\end{array}$ & No & --- \\
\hline Tumor size $(\mathrm{cm})$ & 10 & 5.2 & 8.8 & 6.2 & 12 & $8.44 \pm 2.77$ \\
\hline Total liver volume $(\mathrm{ml})$ & 1794 & 1290 & 1180 & 1300 & 1026 & $1318 \pm 288.09$ \\
\hline Expected remnant liver volume $(\mathrm{ml})$ & 446 & 279 & 350 & 392 & 306 & $354.6 \pm 66.8$ \\
\hline Expected remnant liver percentage (\%) & 24.9 & 21.6 & 29.7 & 30.2 & 29.8 & $27.24 \pm 3.83$ \\
\hline Liver to lung shunt fraction $(\%)$ & 6.56 & 2.56 & 5.32 & 2.6 & 11.6 & $5.83 \pm 3.71$ \\
\hline \multicolumn{7}{|c|}{ Radiological and volumetric evaluations after TARE/before liver resection } \\
\hline Tumor size $(\mathrm{cm})$ & 8 & 4.5 & 6.8 & 5.3 & 5.8 & $6.08 \pm 1.36$ \\
\hline$\%$ Tumor shrinkage & 20 & 13.5 & 22.7 & 14.5 & 51.7 & $24.48 \pm 15.69$ \\
\hline Expected remnant liver volume $(\mathrm{ml})$ & 689 & 358 & 447 & 600 & 410 & $500.8 \pm 138.56$ \\
\hline Expected remnant liver percentage $(\%)$ & 38.4 & 27.8 & 37.9 & 46.2 & 40 & $38.06 \pm 6.62$ \\
\hline$\%$ Expected remnant liver hypertrophy & 54.5 & 28.3 & 27.7 & 53.1 & 34 & $39.52 \pm 13.27$ \\
\hline
\end{tabular}

INR, international normalized ratio; AST, aspartate aminotransferase; ALT, alanine aminotransferase; AFP, alpha fetoprotein; PIVKA-II, protein induced by vitamin $\mathrm{K}$ absence or antagonist-II; TARE, trans-arterial radio-embolization

mean hospital stay was $13.8 \pm 4.1$ days. One patient $(20 \%)$ developed postoperative morbidity. This patient developed postoperative fascial defect in the abdominal wound that required operative repair (Grade III, according ClavienDindo classification).

Pathologically, the mean tumor necrosis percentage was $89.4 \pm 16.9 \%$. R0 resection was achieved in all cases, and the mean resection margin was $21.8 \pm 18.9 \mathrm{~mm}$. The mean follow-up duration was $15 \pm 2.7$ months. All patients were alive at the time of the follow up. None of the patients experienced tumor recurrence at the time of the follow up.

\section{Changes in liver functions and tumor markers}

Changes in serum liver functions and tumor markers before and after both TARE therapy and liver resection are shown in Fig. 3.
No marked changes in serum bilirubin was noted before and after both TARE therapy and liver resection. Mean serum bilirubin changed from $0.6 \mathrm{mg} / \mathrm{dl}$ before TARE therapy to $0.7 \mathrm{mg} / \mathrm{dl}$ after TARE therapy to $0.6 \mathrm{mg} / \mathrm{dl}$ preoperatively to $0.8 \mathrm{mg} / \mathrm{dl}$ postoperatively.

Serum alanine aminotransferase (ALT) did not show marked changes before and after both TARE therapy and liver resection. Mean serum ALT changed from 56.4 IU/L before TARE therapy to $55.8 \mathrm{IU} / \mathrm{L}$ after TARE therapy to $30.2 \mathrm{IU} / \mathrm{L}$ preoperatively to $29.4 \mathrm{IU} / \mathrm{L}$ postoperatively. Mean serum aspartate aminotransferase (AST) increased from 58.6 IU/L before TARE therapy to $80.8 \mathrm{IU} / \mathrm{L}$ after TARE therapy. Mean serum AST did not change markedly before and after liver resection (30.2 and 29.4 IU/L, respectively).

Serum tumor markers showed dramatic decrease after 
Table 2. Peri-operative and Pathological data of the study patients

\begin{tabular}{|c|c|c|c|c|c|c|}
\hline Variables & Case 1 & Case 2 & Case 3 & Case 4 & Case 5 & All cases \\
\hline Interval between TARE and resection & 47 & 44 & 101 & 142 & 164 & $99.6 \pm 54.33$ \\
\hline Operation type & RH & RH & RH & Extended RH & RH & --- \\
\hline Operation time (minutes) & 230 & 105 & 120 & 180 & 120 & $151 \pm 52.7$ \\
\hline Estimated blood loss (ml) & 50 & 100 & 50 & 50 & 30 & $56 \pm 26.1$ \\
\hline Blood transfusion & No & No & No & No & No & --- \\
\hline Intraoperative complications & No & No & No & No & No & --- \\
\hline Hospital stay (days) & 9 & 39 & 7 & 7 & 7 & $13.8 \pm 4.1$ \\
\hline Postoperative morbidity & No & Yes & No & No & No & --- \\
\hline Clavien-Dindo grade & & IIIb & & & & \\
\hline \multicolumn{7}{|l|}{ Pathological data } \\
\hline Liver status & $\begin{array}{l}\text { Chronic } \\
\text { hepatitis }\end{array}$ & $\begin{array}{l}\text { Chronic } \\
\text { hepatitis }\end{array}$ & $\begin{array}{l}\text { Mixed } \\
\text { cirrhosis* }\end{array}$ & $\begin{array}{l}\text { Micro } \\
\text { cirrhosis }\end{array}$ & Normal & --- \\
\hline Type & $\begin{array}{l}\text { Expanding } \\
\text { nodular }\end{array}$ & Mass forming & Trabecular & NA & NA & --- \\
\hline Edmonson-Steiner grade & II & II & II & NA & NA & --- \\
\hline Necrosis percentage $(\%)$ & 60 & 97 & 90 & $\begin{array}{l}100 \text { (totally } \\
\text { necrotic) }\end{array}$ & $\begin{array}{l}100 \text { (totally } \\
\text { necrotic) }\end{array}$ & $89.4 \pm 16.94$ \\
\hline Resection margin & R0 & $\mathrm{R} 0$ & $\mathrm{R} 0$ & R0 & R0 & --- \\
\hline Margin length (mm) & 39 & 6 & 43 & 1 & 20 & $21.8 \pm 18.91$ \\
\hline Capsule & Partial & Partial & Complete & NA & NA & --- \\
\hline Satellite nodules & No & No & No & No & No & --- \\
\hline Microvascular invasion & Yes & No & No & NA & NA & --- \\
\hline Perineural invasion & No & No & No & NA & NA & --- \\
\hline \multicolumn{7}{|l|}{ Survival outcomes } \\
\hline Follow up duration (months) & 19 & 16 & 15 & 13 & 12 & $15 \pm 2.74$ \\
\hline Survival & Alive & Alive & Alive & Alive & Alive & --- \\
\hline Recurrence & No & No & No & No & No & --- \\
\hline Recurrence free survival (months) & 19 & 16 & 15 & 13 & 12 & $15 \pm 2.74$ \\
\hline
\end{tabular}

*Mixed cirrhosis: mixed micro- and macro-nodular cirrhosis

${ }^{\dagger}$ Micro cirrhosis: micro-nodular cirrhosis

TARE, trans-arterial radio-embolization; RH, right hemi-hepatectomy

TARE therapy and continued to decrease after liver resection. Mean serum AFP decreased from $5887.6 \mathrm{ng} / \mathrm{ml}$ before TARE therapy to $816.7 \mathrm{ng} / \mathrm{ml}$ after TARE therapy to $18.42 \mathrm{ng} / \mathrm{ml}$ preoperatively to $3.52 \mathrm{ng} / \mathrm{ml}$ postoperatively. Similarly, mean serum PIVKA-II decreased from $7335.6 \mathrm{mAU} / \mathrm{ml}$ before TARE therapy to 1641.9 $\mathrm{mAU} / \mathrm{ml}$ after TARE therapy to $669.8 \mathrm{mAU} / \mathrm{ml}$ preoperatively to $25.4 \mathrm{mAU} / \mathrm{ml}$ postoperatively.

\section{DISCUSSION}

Surgical management of HCC patients is a challenging scenario. More than $90 \%$ of HCC cases develop on a background of chronic liver disease. ${ }^{21-23}$ This limits the resectability of HCC due to the need to preserve a sufficient remnant liver volume to avoid the development of posthepatectomy liver failure.
Yttrium-90 TARE is an image guided locoregional therapeutic option for patients with hepatic malignancies not suitable for curative liver resection. It involves selective injection of yttrium-90-labelled microspheres through hepatic arteries. This provides selective internal radiation to the tumor sparing the normal liver parenchyma resulting in progressive tumor necrosis and shrinkage. $^{24,25}$ Yttrium-90 TARE had shown good outcomes in the management of intermediate and advanced stage HCC. ${ }^{11,12}$

From the surgical view, TARE therapy may help to increase resectability of HCC in high risk patients with initial small ERLV. In the current study, we evaluated our initial experience of the bridging role of TARE before major liver resection for $\mathrm{HCC}$ in high risk patients with initial small ERLV.

TARE therapy induces hypertrophy of ERLV before 
Changes of bilirubin

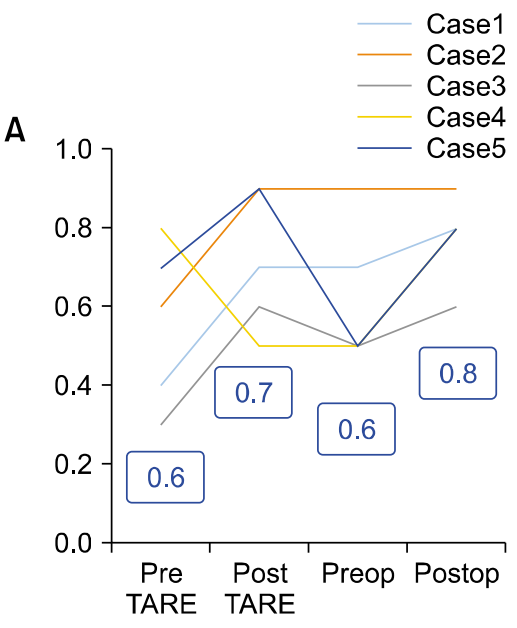

Changes of AFP

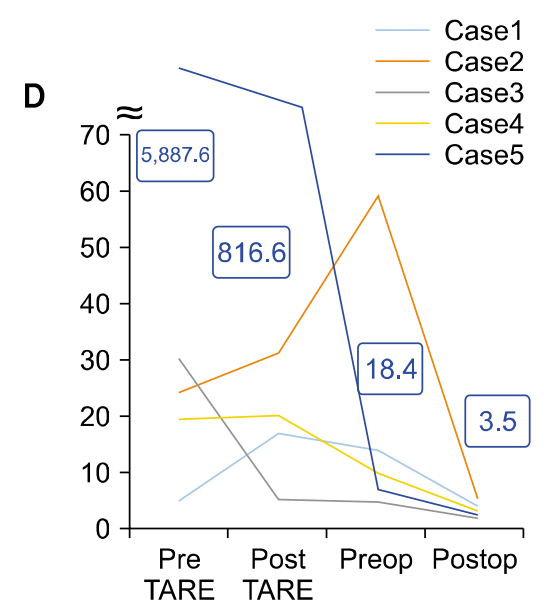

Changes of ALT

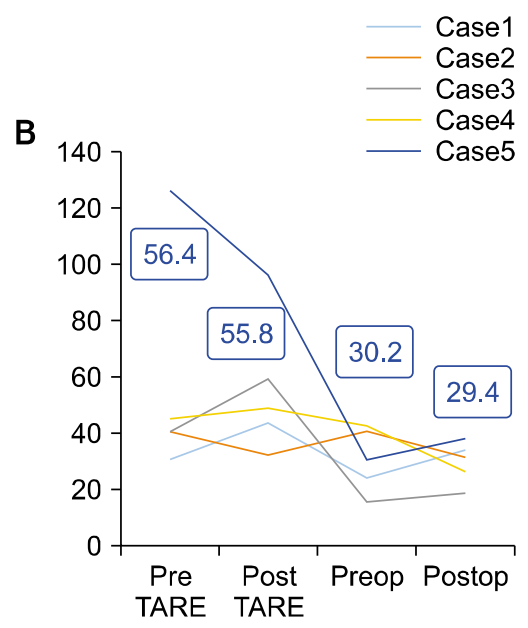

Changes of PIVKA-II

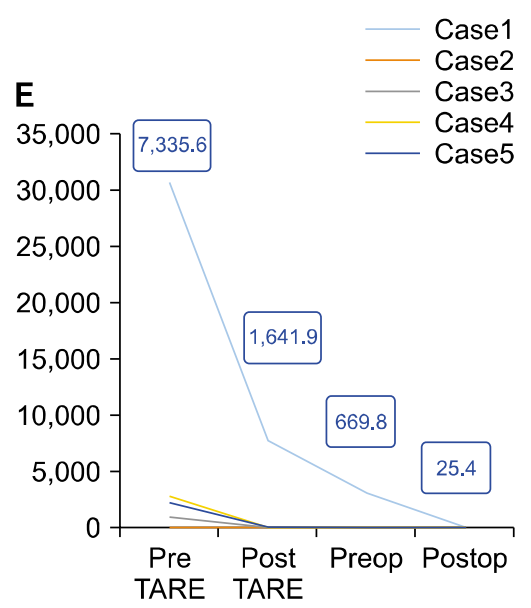

Fig. 3. Changes in serum liver functions and tumor markers during management protocol. (A) Changes in serum bilirubin. (B) Changes in serum alanine aminotransferase (ALT). (C) Changes in serum aspartate aminotransferase (AST). (D) Changes in serum alpha fetoprotein (AFP). (E) Changes in serum protein induced by vitamin $\mathrm{K}$ absence or antagonist-II (PIVKA-II). TARE, trans-arterial radio-embolization; Op, operation.

liver resection. The underlying mechanism for this is the atrophy-hypertrophy phenomenon, which refers to the liver's response to cellular loss by controlled restoration of the liver parenchyma. ${ }^{26}$ Yttrium-90-labelled microspheres induces gradual damage of the irradiated liver with gradual fibrosis and tumor shrinkage by combination of high dose radiation in and around the vascular tumor bed and by micro-arterial embolization. ${ }^{27}$ Subsequently, decreasing the portal flow to the irradiated hemi-liver and redirecting the portal flow to the nonirradiated hemi-liver. Portal flow modulation stimulates release of growth factors and cytokines in the non-irradiated hemi-liver. ${ }^{28}$ Testing the regenerative capacity of the liver is important clinical guide, especially in patients with fibrosis or cirrhosis, in making decision to proceed for safe liver resection or not.

Vouche et al. ${ }^{14}$ reported increase in the \% expected remnant liver hypertrophy up to $35 \%$ after TARE therapy. Lewandowski et al. ${ }^{15}$ reported that the \% expected remnant liver hypertrophy increased significantly after TARE therapy up to $30 \%$. Edeline et al. ${ }^{29}$ reported increase in the $\%$ ERLV of $42 \%$ after TARE therapy. In our study, the expected remnant liver percentage improved from $27.2 \%$ to $38.1 \%$ after TARE therapy $(p=0.004)$, and the $\%$ expected remnant liver hypertrophy was $39.5 \%$.

The improvement of the ERLV following TARE therapy is comparable to this achieved with standard preoperative PVE, however the kinetics of volume hypertrophy is slower in TARE therapy compared to PVE. 
Shindoh et al. ${ }^{30}$ reported approximately $30 \%$ increase of the expected remnant liver percentage at 4-8 weeks after PVE. Farges et al. ${ }^{31}$ reported increased expected remnant liver percentage up to $47 \%$ in normal livers and up to $47 \%$ in chronic liver disease at 4-8 weeks after PVE.

The main advantage of TARE therapy compared to standard PVE that it provides a good control of the tumor during the waiting period for remnant liver volume hypertrophy. This provides a good biologic test to evaluate the tumor response after TARE therapy. The biologic behavior of the tumor is another important clinical guide in making decision to proceed for liver resection. Patients showing aggressive tumor behavior in terms of disease progression are not good candidates for resection. ${ }^{14}$ In our study, we did not experience disease progression during the interval between TARE therapy and adequate remnant liver volume achievement, so we proceeded to liver resection in all of our cases.

The ideal time interval between TARE therapy and liver resection is debatable issue. Previous studies have addressed that a time interval of 3 to 6 months is adequate to achieve a sufficient remnant liver volume hypertrophy. ${ }^{13-15}$ In our study, the mean interval between TARE therapy and liver resection was almost 100 days. In the beginning of our experience, we proceeded to liver resection at earlier time interval based on radiological evaluation of achievement of sufficient remnant liver volume hypertrophy and adequate devascularization of the tumor. Also, this time interval provides a good safety for surgeons and paramedics from radiation exposure during liver resection. Afterwards, we changed our policy to wait for almost 3 months interval allowing for more tumor control and remnant liver volume improvement.

Several post-TARE complications had been addressed. These complications include radioembolization-induced liver disease, biliary complications, radiation pneumonitis, pancreatitis and peptic ulcers. ${ }^{32}$ Previous studies had reported that severe post-TARE complications occur in less than $9 \%$ off the patients, and the incidence of complications that may require intervention is low. ${ }^{13,14,31}$ In our study, none of the patients developed any adverse events related to irradiation or required post-TARE interventions. Post-TARE complications can be avoided or minimized by appropriate multi-disciplinary patient selection, careful treatment planning, and accurate dose administration. The low incidence of post-TARE complications proves the safety of TARE therapy as a bridge for to liver resection.

Major liver resection after TARE therapy is technically challenging. Vouche et al. ${ }^{14}$ addressed that of increased inflammation and induration of surgical planes and liver parenchyma are the main surgical issues encountered during liver resection following TARE therapy. They adopted the use of sharp dissection rather than their routine approach. In our experience, we did not face a great surgical difficulty during the liver resection following TARE therapy. Perihepatic inflammatory adhesions were found and were easily dissected without injuries to any surrounding organs. Demarcation between treated and nontreated hemi-liver was evident. Pedicle dissection and control of inflow structures was easily done without marked inflammatory changes at the hepatic pedicle. The estimated blood loss was minimal (mean $56 \mathrm{ml}$ ) and none of our patients required blood transfusions.

Postoperatively, one patient (20\%) developed severe postoperative morbidity in the form of abdominal wound dehiscence that required operative repair. Previous studies had reported incidence of major complications after liver resection following TARE around $16-38 \%{ }^{13-15}$ Generally, the perioperative outcomes of liver resection following TARE therapy is similar to the outcomes after liver resection without preoperative TARE therapy. ${ }^{22,33}$

Pathological examination of liver specimens following liver resection showed a mean tumor necrosis percentage of $89.4 \%$. Complete tumor necrosis was noticed in only 2 patients $(40 \%)$ on pathological examination despite complete tumor devascularization and lack of viable tumor on preoperative radiological studies. Gabr et al. ${ }^{13}$ reported complete tumor necrosis in $45 \%$ of the patients on pathological examination. Lewandowski et al. ${ }^{15}$ reported complete tumor necrosis in only $33 \%$ of the patients on pathological examination. Residual viable tumor is usually found on post resection pathological examination. This sheds light on the importance of proceeding to liver resection after TARE therapy and not depending on complete tumor devascularization on preoperative radiological examination.

The long-term outcomes of HCC patients who underwent liver resection after TARE is still unclear. Only one study addressed survival outcomes of HCC patients who underwent liver resection after TARE. The median fol- 
low-up duration was 13 months (8-22 months), and the 1 - and 3 -years survival rates were $96 \%$ and $86 \%$, respectively. The median recurrence-free survival was 34.2 months. ${ }^{13}$ Our study is limited by the short follow up duration; however, after a mean follow-up duration of 15 months, all patients were alive with no recurrences. The mean recurrence-free survival 15 months (12-19 months).

Our study has some limitations including its retrospective design with inherent selection bias and including a small number of patients. Our study lacked comparative analysis with primary resection or sequential TACE \& PVE before liver resection or with HCC patients who did not underwent liver resection. Also, cost analysis of TARE therapy was not evaluated. However, in our study we aimed to evaluate our initial experience of the bridging role of TARE before major liver resection for borderline resectable HCC cases with small ERLV. The results of our study endorsed us to expand the indications of TARE therapy from unresectable $\mathrm{HCC}$ cases to borderline and resectable HCC cases. Currently, we are conducting a prospective study evaluating the safety and efficacy of TARE before liver resection for patients with large HCC more than $5 \mathrm{~cm}$ in largest diameter.

In conclusion, yttrium-90 TARE therapy can play an important bridging role before major liver resection for borderline resectable HCC in high risk patients with small ERLV. It could achieve adequate remnant liver volume hypertrophy (safety aspect), while downstaging and controlling the primary tumor (oncologic aspect). A prospective comparative study with primary liver resection or sequential TACE \& PVE before liver resection is needed to evaluate the short- and long-term outcomes of those approaches.

\section{ETHICAL STATEMENT}

We confirm that all authors declare no conflicts of interest. An informed consent was obtained from all individual participants included in the study. The current study was approved by institutional review board of Seoul National University Hospital, Seoul National University, Korea.

\section{CONFLICT OF INTEREST}

All authors declare no conflicts of interest.

\section{ORCID}

Ahmed Shehta: https://orcid.org/0000-0002-9184-8597

Jeong-Moo Lee: https://orcid.org/0000-0001-7806-8759

Kyung-Suk Suh: https://orcid.org/0000-0002-9535-7349

Hyo-Cheol Kim: https://orcid.org/0000-0002-6016-247X

Suk Kyun Hong: https://orcid.org/0000-0002-0020-6215

Jae-Hyung Cho: https://orcid.org/0000-0003-0188-8278

Nam-Joon Yi: https://orcid.org/0000-0002-5467-425X

Kwang-Woong Lee: https://orcid.org/0000-0001-6412-1926

\section{AUTHOR CONTRIBUTIONS}

Conceptualization: JML, KSS. Data curation: HCK, SKH, JHC, NJY, KWL. Methodology: AS, JML. Visualization: AS, JML. Writing - original draft: AS, JML. Writing review \& editing: KSS.

\section{REFERENCES}

1. Byam J, Renz J, Millis JM. Liver transplantation for hepatocellular carcinoma. Hepatobiliary Surg Nutr 2013;2:22-30.

2. Li X, Huang L, Leng X. Analysis of prognostic factors of more/equal to 10 years of survival for liver cancer patients after liver transplantation. J Cancer Res Clin Oncol 2018;144:24652474.

3. Cauchy F, Soubrane O, Belghiti J. Liver resection for HCC: patient's selection and controversial scenarios. Best Pract Res Clin Gastroenterol 2014;28:881-896.

4. Makuuchi M, Thai BL, Takayasu K, Takayama T, Kosuge T, Gunvén $\mathrm{P}$, et al. Preoperative portal embolization to increase safety of major hepatectomy for hilar bile duct carcinoma: a preliminary report. Surgery 1990;107:521-527.

5. de Graaf W, van den Esschert JW, van Lienden KP, van Gulik TM. Induction of tumor growth after preoperative portal vein embolization: is it a real problem? Ann Surg Oncol 2009;16:423430.

6. Heinrich S, Jochum W, Graf R, Clavien PA. Portal vein ligation and partial hepatectomy differentially influence growth of intrahepatic metastasis and liver regeneration in mice. J Hepatol 2006;45:35-42.

7. Hayashi S, Baba Y, Ueno K, Nakajo M, Kubo F, Ueno S, et al. Acceleration of primary liver tumor growth rate in embolized hepatic lobe after portal vein embolization. Acta Radiol 2007;48: 721-727.

8. Aoki $\mathrm{T}$, Imamura $\mathrm{H}$, Hasegawa $\mathrm{K}$, Matsukura A, Sano K, Sugawara Y, et al. Sequential preoperative arterial and portal venous embolizations in patients with hepatocellular carcinoma. Arch Surg 2004;139:766-774. 
9. Mason MC, Massarweh NN, Salami A, Sultenfuss MA, Anaya DA. Post-embolization syndrome as an early predictor of overall survival after transarterial chemoembolization for hepatocellular carcinoma. HPB (Oxford) 2015;17:1137-1144.

10. Blackburn H, West S. Management of postembolization syndrome following hepatic transarterial chemoembolization for primary or metastatic liver cancer. Cancer Nurs 2016;39:E1-E18.

11. Memon K, Kulik L, Lewandowski RJ, Mulcahy MF, Benson $\mathrm{AB}$, Ganger D, et al. Radioembolization for hepatocellular carcinoma with portal vein thrombosis: impact of liver function on systemic treatment options at disease progression. J Hepatol 2013;58:73-80.

12. Wang EA, Stein JP, Bellavia RJ, Broadwell SR. Treatment options for unresectable HCC with a focus on SIRT with Yttrium90 resin microspheres. Int J Clin Pract 2017;71:e12972.

13. Gabr A, Abouchaleh N, Ali R, Baker T, Caicedo J, Katariya N, et al. Outcomes of surgical resection after radioembolization for hepatocellular carcinoma. J Vasc Interv Radiol 2018;29:15021510.e1.

14. Vouche M, Lewandowski RJ, Atassi R, Memon K, Gates VL, Ryu RK, et al. Radiation lobectomy: time-dependent analysis of future liver remnant volume in unresectable liver cancer as a bridge to resection. J Hepatol 2013;59:1029-1036.

15. Lewandowski RJ, Donahue L, Chokechanachaisakul A, Kulik L, Mouli S, Caicedo J, et al. 90Y radiation lobectomy: outcomes following surgical resection in patients with hepatic tumors and small future liver remnant volumes. J Surg Oncol 2016;114:99105.

16. Yang X, Yu HC, Choi Y, Lee W, Yang J, Hwang H, et al. Development and usability testing of Dr. LiverTM: a user-centered 3D virtual liver surgery planning system. Proc Hum Factors Ergon Soc Annu Meet 2014;58:698-702.

17. Kim HC, Kim YJ, Paeng JC, Chung JW. Yttrium-90 radioembolization of the right inferior phrenic artery in 20 patients with hepatocellular carcinoma. J Vasc Interv Radiol 2018;29: 556-563.

18. Kim HC, Kim YJ, Lee JH, Suh KS, Chung JW. Feasibility of boosted radioembolization for hepatocellular carcinoma larger than $5 \mathrm{~cm}$. J Vasc Interv Radiol 2018;30:1-8.

19. Lencioni R, Llovet JM. Modified RECIST (mRECIST) assessment for hepatocellular carcinoma. Semin Liver Dis 2010;30:5260.

20. Dindo D, Demartines N, Clavien PA. Classification of surgical complications: a new proposal with evaluation in a cohort of
6336 patients and results of a survey. Ann Surg 2004;240:205213.

21. Gluer AM, Cocco N, Laurence JM, Johnston ES, Hollands MJ, Pleass HC, et al. Systematic review of actual 10-year survival following resection for hepatocellular carcinoma. HPB (Oxford) 2012;14:285-290.

22. Bruix J, Sherman M. Management of hepatocellular carcinoma: an update. Hepatology 2011;53:1020-1022.

23. Forner A, Llovet JM, Bruix J. Hepatocellular carcinoma. Lancet 2012;379:1245-1255.

24. Henry LR, Hostetter RB, Ressler B, Bowser I, Yan M, Vaghefi $\mathrm{H}$, et al. Liver resection for metastatic disease after y90 radioembolization: a case series with long-term follow-up. Ann Surg Oncol 2015;22:467-474.

25. Salem R, Mazzaferro V, Sangro B. Yttrium 90 radioembolization for the treatment of hepatocellular carcinoma: biological lessons, current challenges, and clinical perspectives. Hepatology 2013; 58:2188-2197.

26. Fidelman N, Kerlan RK Jr. Transarterial chemoembolization and $90 Y$ radioembolization for hepatocellular carcinoma: review of current applications beyond intermediate-stage disease. AJR Am J Roentgenol 2015;205:742-752.

27. Wang LM, Jani AR, Hill EJ, Sharma RA. Anatomical basis and histopathological changes resulting from selective internal radiotherapy for liver metastases. J Clin Pathol 2013;66:205-211.

28. Kim RD, Kim JS, Watanabe G, Mohuczy D, Behrns KE. Liver regeneration and the atrophy-hypertrophy complex. Semin Intervent Radiol 2008;25:92-103.

29. Edeline J, Lenoir L, Boudjema K, Rolland Y, Boulic A, Le Du $\mathrm{F}$, et al. Volumetric changes after $90 \mathrm{y}$ radioembolization for hepatocellular carcinoma in cirrhosis: an option to portal vein embolization in a preoperative setting? Ann Surg Oncol 2013;20: 2518-2525.

30. Shindoh J, D Tzeng CW, Vauthey JN. Portal vein embolization for hepatocellular carcinoma. Liver Cancer 2012;1:159-167.

31. Farges O, Belghiti J, Kianmanesh R, Regimbeau JM, Santoro R, Vilgrain V, et al. Portal vein embolization before right hepatectomy: prospective clinical trial. Ann Surg 2003;237:208-217.

32. Riaz A, Awais R, Salem R. Side effects of yttrium-90 radioembolization. Front Oncol 2014;4:198.

33. Nguyen KT, Gamblin TC, Geller DA. World review of laparoscopic liver resection-2,804 patients. Ann Surg 2009;250:831841. 